\title{
Um espaço adaptado, habitado e filmado: expansões de uma memória através de sua recriação estética
}

\author{
Juliano Rodrigues Pimentel \\ Universidade Federal do Rio Grande do Sul
}

Resumo: Este estudo tem como tema a adaptação fílmica e suas implicações estéticas e audiovisuais relacionadas a uma ampliação de uma memória de um objeto cultural. Trago como objetos empíricos o conto Pela passagem de uma grande dor, de Caio Fernando Abreu, e sua adaptação homônima para o formato audiovisual. À luz da Poética do espaço de Gaston Bachelard, analiso as imagens do conto adaptado e apresento uma estética particular proposta pelo curta como proponente de uma ampliação da memória cultural do objeto-fonte.

Palavras-chave: adaptação; estética; filme; curta. 


\title{
An adapted inhabited and filmed space: expansions of memory through its aesthetic recreation
}

\begin{abstract}
This study is centered at an investigation about filmic adaptation and its aesthetical and filmic implications related to an amplification of a cultural memory of an object. The analysis that supports the claim that the adaptation process amplifies the cultural memory considers the short story by Caio Fernando Abreu, Pela passagem de uma grande dor, and its filmic adaptation by the same name. The hypothesis the study present is that, supported by Bachelard's theory of the Poetic Space, the filmic aesthetics, as it recreates the short story, enables it to be viewed as something broader.
\end{abstract}

Keywords: adaptation; aesthetics; film; short subject film.

\section{Un espacio adaptado, habitado y filmado: expansiones de memoria a través de su recreación estética}

Resumen: Este estudio tiene como tema la adaptación cinematográfica y su estética e implicaciones audiovisuales relacionados con una extensión de una memoria cultural . Como objetos empíricos propongo el cuento Pela passagem de uma grande dor, de Caio Fernando Abreu, y su homónima adaptación a formato audiovisual. A la luz de la poética del espacio, de Gaston Bachelard, analizo las imágenes de la historia adaptada y presento la idea de que una estética particular permite la extensión de la memoria cultural de un objecto cultural previamente establecido.

Palabras-clave: adaptación; estética; film; corto. 


\section{Considerações iniciais}

No início da década de 50, André Bazin propõe um ensaio em defesa de um cinema impuro, capaz de estabelecer um diálogo não belicoso com a literatura. Ele comenta que "o romance requeria uma certa margem de criação para passar da escritura à imagem” (Bazin, 1991:83), algo que apropriação da literatura pela cinema possibilita. Essa perspectiva vai à direção contrária do pensamento de outros teóricos de sua época, como Jean Epstein, que defendia um cinema puro e não contaminado por influencias "estrangeiras" ao cinema. Goerge Bluestone, em 1961, em um ensaio que buscava legitimar os estudos de adaptação como campo de estudo, apontou para que se observasse os filmes e a literatura de maneira separada, cada um atingindo seus resultados únicos através dos intrincados jogos simbólicos, conceituais e discursivos inerentes a suas próprias especificidades únicas. Por sua vez, David Bordwell (1991), comenta que há uma aproximação entre o cinema e a literatura em diversas ocasiões históricas e com os mais diversos graus de proximidade, sendo que ambos se favorecem dessa relação, desde os romances "ruins" da década de 20 e 30 que geraram bons filmes, até os bons romances que ganharam uma sobrevida em filmes medianos nas grandes telas. Barton Palmer (2004), já dentro de um escopo institucionalizado da pesquisa em adaptação, fala que o elemento chave para compreender a adaptação e o trânsito entre adaptação e sua conformação em uma expressão audiovisual está na relação intertextual entre as partes e na maneira como esse processo reinterpreta e reimagina o objeto fonte. Fora de uma perspectiva acadêmica, e de certa forma legitimando a impuridade do objeto adaptado, a própria premiação do Academy Awards of Motion Picture Arts and Sciences desde a década de 20 premia com um Oscar o filme de melhor roteiro adaptado.

Este breve panorama, um dos muitos possíveis quando se trata da perspectiva audiovisual sobre suas relações intertextuais com outros objetos da cultura, visa amparar o questionamento que guia este estudo: como o processo adaptativo amplia as possibilidades de uma memória cultural de uma narrativa?

Parto da hipótese de que ao estudar o processo adaptativo e mergulhar nas suas questões centrais, podemos observar que apropriação do objeto e sua conformação segundo os instrumentos e devires estéticos de um outro meio de expressão causam uma expansão nas possíveis maneiras de imaginar e se relacionar com um objeto já existente. Isso aparenta ocorrer por causa de um desejo de memória-repetição de um objeto já existente, mas também, talvez em igual parte, um desejo de mudança que também acompanha a repetição. Essa hipótese surge a partir da análise e apreciação crítica do conto Pela passagem de uma grande dor (1983), de Caio Fernando Abreu, e sua adaptação fílmica realizada por Bruno Polidoro (2005). Este estudo busca explorar uma construção estética que no objeto adaptado se pauta por uma poética do existir ou uma estética do habitar, que não aparece necessariamente no objeto fonte (literário), mas que abriga a narrativa literária através das potencialidades imagéticas do formato fílmico, assim lhe garantindo uma nova interpretação e um novo jeito de ser lembrado. 
Inúmeros autores trabalham com as poéticas individuais do habitar e da criação de marcas pessoais que tornam um lugar qualquer uma casa, ou um ninho, contudo opto por tratar dessas questões na sua possível proximidade com os estudos da imagem audiovisual a partir do texto $A$ poética do espaço (2012), de Gaston Bachelard, por se tratar de uma fonte rica e capaz de propor uma ponte natural entre a simbologia e poética da imagem literária e suas potencialidades percebidas em imagens de outros formatos.

O que justifica um empenho teórico nesta direção me parece ser a necessidade colaborar com a multiplicidade de entendimentos sobre as implicações antropológicas da criação ficcional. Esse entendimento também enriquece o arcabouço teórico sobre o processo de criação na medida em que se explora a maneira como criamos imagens de conceitos que nos são bastante caros enquanto consumidores de nossas próprias marcas identitárias e também como manifestamos nossa própria cultura, lidamos com desejos de diferença e repetição nas narrativas que (re)criamos e delegamos a um processo adaptativo novas elaborações estéticas de determinados produtos midiáticos balizadas por diferentes motivações.

Se assumirmos como verdadeira a hipótese ${ }^{2}$ de que a obra Morangos Mofados (1983) do escritor Caio Fernando Abreu, representada neste estudo pelo conto Pela passagem de uma grande dor (Abreu, 1983), constitui um marco da expressão e identidade cultural que retrata sua época de escrita com uma grande competência estética, então me parece relevante observar como as questões impostas pelos elementos constitutivos da estética audiovisual recriam, negociam, alteram e captam as reverberações deste momento estético e cultural anterior.

\section{Dos objetos empíricos e as perspectivas adaptativas}

Caio Fernando Loureiro de Abreu3 foi um escritor gaúcho, nascido em 1948, na cidade de Santiago. Faleceu em Porto Alegre, no ano de 1996, por decorrências do HIV. Sua carreira começa em 1963, com a publicação do conto O príncipe sapo, na revista Cláudia e não cessa até o fim de sua vida Em seus escritos é possível encontrar trabalhos como cronista, tradutor, romancista, dramaturgo, mas, majoritariamente, como contista. Caio viveu e vivenciou diversas cidades no Brasil e no mundo. Isso aparece em vários pontos de sua obra, fato esse que interessa de maneira particular para essa pesquisa, pois os espaços trazidos para dentro de sua obra literária são os mais diversos, assim como a incerteza da relação entre o habitante e o habitado. Dos concretos aos fantasiosos, o autor parece ter norteado muita da sua ficção pela busca de um lugar para que a solidão dos personagens habite. $O$ pesquisador e diretor de cinema, Fabiano de Souza, em seu livro Caio Fernando Abreu e o Cinema (2011), apresenta o escritor gaúcho dentro de um contexto cinematográfico, não por uma inserção direta, entretanto através das diferentes simbologias encontradas por ele em suas análises:

Em contos, cartas, novelas, romances e crônicas, Caio sempre trouxe a cultura audiovisual para o primeiro plano. Personagens vão ao cinema, principalmente

\footnotetext{
${ }_{2}^{2}$ Posicionamento este balizado por estudos anteriores, tais como: Pimentel (2015), Souza (2011) e Porto (2005). Referências bibliográficas encontradas

http://www itaucultural org br/aplicexternas/enciclopedia_lit/index.cfm?fuseaction=biografias_texto\&cd_verbete=50 em 6. 69. Acessado em 12/11/2013, 13/10/2014 e 20/05/2015
} 


\begin{abstract}
aqueles que não têm família para matar. O mundo destes seres muitas vezes já é impregnado de imagens, a vida parece um filme, uma rosa púrpura. O texto também vem de dentro do celuloide e traz processos estilísticos próprios do cinema - frases parecem descrever posições de câmera, passagens inteiras lembram, como num filme, que o olhar é a ação objetiva mais subjetiva que existe. Entre citações e referências, constrói-se um panteão de diretores eleitos, preferidos. No meio de tudo, textos e textos de Caio Fernando Abreu aguardando, pedindo, clamando para serem levados à tela (Souza, 2011:12)
\end{abstract}

A caneta, a máquina de escrever de Caio Fernando Abreu não é uma câmera, mas parece uma. As imagens descritas em seus contos ganham perspectivas semelhantes à maneira como as lentes de uma câmera descreve uma cena à sua frente. Assim como Caio F. compartilha dos elementos componentes de um universo estético habitado por devires da própria imagem audiovisual, as imagens adaptadas de seu conto dialogam com os códigos estéticos propostos pelo próprio autor. $\mathrm{O}$ que esta passagem nos possibilita começar a contemplar é o fato de que, ao pensarmos uma adaptação, não está em jogo apenas um objeto-fonte e um objeto adaptado, mas toda uma teia de relação em que o objeto fonte está inserido e que contribuem para sua composição estética original e também na nova conformação adaptada.

Nestas linhas, o pesquisador e diretor de cinema, Fabiano de Souza, propõe que "há o estabelecimento de um diálogo de universos, não a simples transposição de um conteúdo"4. Esse código estabelece um conjunto de símbolos e simbologias que fazem parte da cultura do escritor gaúcho; aparecem em suas histórias e, em alguns exemplos, acabam sendo um ferrolho estético. Como o próprio Souza propõe, o método de Caio traz uma câmera junto da caneta. Os vestígios desse código cultural de Caio F. aparecem em múltiplos contos. Um exemplo disso pode ser encontrado em uma passagem de Saudade de Audrey Hepburn, quinto capítulo de Os dragões não conhecem o paraíso (2005).

\footnotetext{
Mas só muito mais tarde, como um estranho flashback premonitório, no meio duma noite de possessões incompreensíveis, procurando sem achar uma peça de Charlie Parker pela casa repleta de feitiços ineficientes, recomporia passo a passo aquela véspera de São João em que tinha sido permitido tê-lo inteiramente entre um blues amargo e um poema de vanguarda. (Abreu, 2005:54)
}

O ponto de vista sobre o cotidiano nesse conto se aproxima de uma sequencialidade fragmentada de eventos; há o uso do flashback, um dispositivo narrativo bastante popular durante um período no cinema e, em alguns casos, ainda hoje; há ecos de uma trilha sonora sendo buscada e executada na música de Charlie Parker e num possível voice over 5 de um poema de vanguarda.

O conto Pela passagem de uma grande dor faz parte de um conjunto de fragmentos literários em forma de conto intitulado Morangos mofados, publicado originalmente em 1983. O livro é dividido em duas partes: O mofo e Os morangos, cada parte contendo nove contos. O mofo é composto pelos seguintes textos: Diálogo, Os sobreviventes, $O$ dia em que Urano entrou em Escorpião, Pela passagem de uma grande dor, Além do ponto, Os companheiros, Terça-feira gorda; Eu, tu, ele; Luz e sombra. Os morangos por: Transformações, Sargento Garcia, Fotografias; Pêra, Uva ou Maçã?; Natureza Viva, Caixinha de música, O Dia em que Júpiter encontrou Saturno, Aqueles Dois e Morangos Mofados.

4 Trecho de uma de suas falas sobre seu filme A última estrada para praia (2011), no curso Filmando Sempre, ministrado pelos realizadores da produtora Rainer, realizado no Cine Santander Cultural, POA-RS, dias 21-3, maio de 2014.

5 Gravação de uma trilha de voz sobre uma imagem. 
Pela passagem de uma grande dor conta a história de um homem, Lui, que, enquanto escuta uma música, atende o telefonema de uma amiga que aparenta estar transtornada com algo, oscilando entre a calma e o desespero. Eles falam de amenidades e ela o convida para sair. Ele opta por não sair, continua falando ao telefone e faz relatos de pequenas coisas ao seu redor. Por fim ela se despede e termina a ligação. O conto é majoritariamente um diálogo. As referências ao espaço são poucas, delimitam-se por objetos e as descrição de onde se encontram e de como são percebidos. Entretanto, dentro das perspectivas mínimas, há uma enorme quantidade de informação sobre questões ligadas à própria juventude dos anos 80: solidão, lidar consigo mesmo, uso de drogas, uso de drogas como uma fuga de algo, não pertencimento a lugar nenhum, abortamento, intimidade. Certamente não são questões únicas da época em que Caio Fernando Abreu escrevia, mas marcavam a transição de uma expressão. O próprio cinema aponta na direção desta transição, o campo, o sertão e a fé que muito marcaram o cinema do final da década de 60 , na década de 80 retoma questões existenciais, pequeno-burguesas e volta-se para dentro do ser humana, e não mais na sua relação com o espaço ou a fé como seu antagonista.

Bruno Polidoro 6 , em 2005, realizou o filme Pela passagem de uma grande dor. Um dos cartões iniciais do filme aponta que é baseado na obra de Caio Fernando Abreu, assim não se intitulando como adaptação propriamente. O curta tem a duração de 16 minutos e 25 segundos, foi gravado no Rio Grande do Sul em formato digital (DV). Seu filme recria o conto com um grau bastante grande de proximidade e propõe um ponto de vista centrado no personagem Lui e, de certa forma, seu apreço por sua solidão.

Uma das questões mais particulares, e ainda pouco exploradas, sobre a adaptação fílmica e seu trânsito da literatura para o formato audiovisual é o que toca a antropologia da ficção em particular a maneira como nos apropriamos de objetos culturais para reescrever nossa própria história e ampliar/modificar a memória e o imaginário sobre determinados pontos de nossa experiência cultural. Trata-se de uma área que possibilita diversas abordagens e parece se configurar como essencialmente multidisciplinar visto que os esforços de diversas áreas do saber ajudam a criar entendimentos com maior relevo sobre os objetos empíricos de interesse.

A pesquisadora Linda Hutcheon (2006) propõe uma leitura do produto adaptado como uma tradução crítica-criativa que passa por um processo de interpretação. Este processo interpretativo se apropria de um objeto anterior ou o recupera, dando-lhe nova roupagem ou simplesmente o colocando em um novo contexto (mesmo que semelhante ao anterior). Uma das questões mais pertinentes nessa atividade, para a autora, é o fato de que "com adaptações, nós sentimos tanto o desejo de repetição quanto o de mudança” (Hutcheon, 2006:08). Este desejo de repetição e mudança dá suporte para a hipótese deste estudo, de que há uma expansão da memória e imaginário através do processo de adaptação. Há uma permanência, no mínimo parcial, do objeto através de sua recriação e memória, e há também uma reimaginação dele através das novas contribuições estéticas atreladas ao processo adaptativo. John Ellis, em um

6 Bruno Polidoro tem uma carreira acadêmica aliada à produção ficcional continuada. Foi diretor de fotografia em mais de dezessete obras. Entre curtas, produtos televisivos e documentários, ele é creditado como diretor em três filmes e como produtor em outros seis6. 
artigo sobre adaptação fílmica publicado no periódico Screen $^{7}$ de 1982, fala sobre um livre existir; uma não hierárquica existência entre um filme e sua fonte literária. Ele aponta ainda que a transposição da literatura para o cinema "deve" ser celebrada como um meio de prolongar um prazer obtido através da reprodução de uma memória que existe através de um diálogo entre ambas as expressões literária e fílmica, mas não de maneira estanque dentro destes dois formatos, mas num diálogo entre as diversas questões que orbitam cada um deles.

Julie Sanders (2005), nota que as obras devem ser encaradas de maneira não apenas presa, mas respeitando o devir de cada expressão: "Embora a obra preexistente, e sua relação intertextual, possam enriquecer nossa compreensão do novo produto cultural adaptado, ele pode não ser inteiramente necessário para nossa fruição, independente do resultado" (Sanders, 2005:22, tradução do autor).

Essa compreensão de que o processo de adaptação equaciona mais de uma fonte aparece em diversas referências bibliográficas, contudo é introduzido de maneira direta por Patrick Cattrysse, no artigo Film (adaptation) as translation (1992), publicado no International Journal of Translation Studies:

\begin{abstract}
Acima de tudo, uma análise descritiva, mais do que prescritiva das práticas de adaptação, no que toca a noção de equivalência, nos leva a conclusão de que a adaptação fílmica, em geral, não se limita a uma fonte. Mas a inúmeras outras fontes e práticas, simultâneas e em diferentes níveis, normalmente servindo como modelos do processo de produção. (Cattrysse, 1992:61, tradução do autor).
\end{abstract}

Cattrysse vai adiante oferecendo um exemplo dessa relação através do cinema Noir, que se debruça sobre contos e romances como base para a adaptação, contudo aparecem recriados através de marcas estilísticas próprias de particularidades fílmicas: quanto ao trabalho de direção de fotografia, recebem um tratamento largamente inspirado no Expressionismo Alemão da década de 20, bem como da fotografia e da pintura americanas da década de $50^{8}$; aspectos como a direção de atores, a produção de locações, o departamento de arte, a música e a representação pictórica atuam governadas por modelos e convenções que fogem ao texto literário. Para o autor, não se configura uma infidelidade se contaminar com as fontes complementares que se somam na criação de uma unidade estética de estilo.

Saër Maty Bâ (2007), ao desenvolver o artigo Problematizing (black) documentary aesthetics: John Akomfrah's use of intertextuality in Seven Songs for Malcolm X, publicado no periódico Sutdies in documentary film (Monash University), reforça a noção estabelecida por Cattrysse (1992), sobre adaptações fílmicas se pautando por múltiplas fontes e efeitos estéticos, e a amplia. O autor nota que o trabalho de construção fílmica e adaptativa pode resultar da priorização de múltiplos textos que orbitam uma dada obra-fonte. Isto ocorre para a finalidade de uma proposta estética que busca adições e complementos através de outras propostas, nem sempre literárias. Bâ (2007) fundamenta este argumento através de um conjunto de comentários feitos sobre a obra Seven songs for Malcolm X (John Akomfrah, 1993). Em sua análise, o filme de Akomfrah (1993) cria sua estética fílmica através de uma experimentação em que elementos sonoros das primeiras manifestações do "jazz negro" corroboram

7 Periódico acadêmico da área da comunicação da Universidade de Glasgow (Escócia) e publicado pela Oxford University Press. Tem como ênfase os temas do cinema, televisão e cultura audiovisual.

${ }^{8}$ Neste caso é possível averiguar uma mútua influência ao redor de, por exemplo, os Nighthawks de Edward Hopper. 
com 'pequenas verdades' estabelecidas pelo diretor. A experiência estética criada pela camada sonora tentada por Akomfrah (1993) carrega o contexto em que o próprio jazz negro foi criado e que se mistura com a própria criação e juventude de Malcolm X: um ambiente cercado por preconceito racial, com condições adversas, mas em que o devir negro se apropriou de formas e estéticas-discursivas estabelecidas pelo americano-europeu. Através dessa tentativa, ainda comenta Bâ (2007), o discurso de libertação estabelecido pelo Jazz, articulado por provocações sonoras e respostas de cada instrumento, ecoa no próprio discurso de liberdade proposto por Malcolm X (BÂ, 2007). Esta consideração sobre a obra de Akomfrah (1993) ajuda a salientar a liberdade criativa com a qual a adaptação fílmica pode lidar.

Considerando as questões trazidas para a discussão teórica sobre o processo de adaptação e as implicações envolvidas nele, nota-se que: a) o processo adaptativo coloca em jogo mais de uma fonte ao recriar uma narrativa em um novo formato; b) as motivações para se optar por uma obra a se adaptar são as mais diversas, contudo elas lidam com um desejo mútuo de repetição e mudança, sendo essa repetição e mudança responsáveis por uma ampliação da memória de uma narrativa e seu contexto estético; c) um dos resultados do processo de adaptação, em particular da forma literária para fílmica, é a criação de uma estética visual não necessariamente presente na obra fonte por ser instrumentalizada pelas potencialidades da própria imagem fílmica. No trecho seguinte deste estudo é contemplada uma análise particular da nova contribuição estética com a qual o filme adaptado Pela passagem de uma grande dor estabeleceu com sua obra-fonte.

\section{Da estética do habitar e das imagens de Pela passagem de uma grande dor}

Uma possível interpretação e análise do curta-metragem Pela passagem de uma grande dor aponta para o isolamento do personagem Lui em seus diferentes espaços. Uma das leituras possíveis aponta para sua reclusão e um apreço pelo isolamento de seu habitar em cada cômodo do apartamento. Desta maneira, construo uma exploração destas imagens a partir das simbologias dos espaços propostos por Bachelard e ancorados pelas possibilidades de organização estética da imagem audiovisual.

A hipótese de uma estética do habitar se dá através de sua fundamentação à partir da $A$ poética do espaço (2012), de Bachelard. Este texto expõe diferentes formulações simbólicas de espaços e habitações, assim como a sua fruição enquanto fomento para uma estética de um determinado espaço e a relação humana de percepção deste espaço. O autor categoriza suas questões de interesse a partir de lugares-chave e compartilha sua percepção como imagem (mental, verbal, visual...). Embora o foco de análise de Bachelard seja o tratamento do espaço em imagem poética, é possível aproximar essas questões de outros tipos de imagem através da apropriação de suas descrições e da funcionalidade das características simbólicas que compreendem cada espaço. A percepção das imagens por Bachelard se dá, aparentemente, em três instâncias: o referencial "real", sua organização como imagem poética e a teia de experiências estéticas que ele utiliza para fruir a imagem. Dentro da proposta de Bachelard está a noção de que a intimidade se constitui na Poética do espaço (2012) como o fio condutor que liga a representação simbólica da imagem de 
um espaço à experiência estética percebida nele. A experiência de habitar um mundo imaginado e com afetos que traduzem espaços em imagens é central no seu discurso na medida em que cada tipo de espaço evoca e referencia simbologias diferentes.

Os espaços simbólicos de Bachelard ocorrem em diferentes tipos de imagem. Tomar-se-ia uma vida toda para catalogar todas as imagens de casa e todas as simbologias que levam uma dada materialidade até um sentimento de casa; uma experiência estética de lar, de habitar um lar e estar preso a ele. Mesmo nesse esforço de uma vida inteira se seria injusto, pois não se contemplaria os "por vir" da própria casa, casas que ainda não existem e as que se desfizeram há muito tempo e só esperam por uma chance para reaparecer. Gaston Bachelard é bastante claro em seu discurso: recolher-se aos pequenos espaços é exercitar a intimidade. Ela não emana apenas de certos tipos de espaço, está atrelada ao habitar desses espaços através de um afeto e uma intensidade que parte de quem o habita. Em suas palavras: "descobrimos aqui que a imensidão íntima é uma intensidade, uma intensidade de ser, a intensidade de um ser que se desenvolve numa vasta perspectiva de imensidão íntima" (Bachelard, 2012:196).

Para aproximar estas questões discutidas por Bachelard das imagens do conto adaptado para o formato fílmico parte-se de uma análise fílmica à luz da proposta de Jullier \& Marie (2009), que propõe em Lendo as imagens do cinema (2009) que "muitos filmes exigem menos ser lidos como mensagens cifradas do que ser sentidos, experimentados carnalmente, ou quase" (Julliler; Marie, 2009:14-15). Trata-se de uma fala que ecoa a metodologia de leitura de imagem proposta por Gaston Bachelard na Poética do espaço (2012). A fenomenologia de leitura da imagem, como proposta por ele ecoa essencialmente essa passagem estabelecida por Jullier \& Marie (2009). Na Poética de Bachelard a fenomenologia que privilegia o sentir ao entender aparece logo nas primeiras páginas:

\begin{abstract}
Perceberemos então que essa transubjetividade 9 da imagem não podia ser compreendida, em sua essência, apenas pelos hábitos das referências objetivas. Só a fenomenologia isto é, a consideração do início da imagem numa consciência individual pode ajudar-nos a reconstituir a subjetividade das imagens e a medir a amplitude, a força, o sentido da transubjetividade da imagem (Julliler; Marie, 2009: $3)$.
\end{abstract}

Buscando instrumentalizar essa perspectiva, proponho o movimento de análise contemplando: o nível do plano fílmico chamando atenção para elementos como o ponto de vista; movimentos de câmera; luzes e cores. No nível da sequência: os pontos de montagem; a cenografia; efeitos gerais de narrativa; efeito de vinheta; metáforas.

Respeitando o fôlego do formato de artigo, trago dois trechos do filme dirigido por Bruno Polidoro, Pela passagem de uma grande dor (2005), que ajudam a compreender criação simbólica do espaço de intimidade que me parece central para uma estética do habitar. Seu filme se passa todo em um ambiente que pode ser compreendido como um apartamento. Nele os espaços são interligados por vãos e ausência de portas fechadas. Embora o personagem Lui estabeleça relações pontuais com cada ambiente da sua moradia, ela possui uma fluidez e unidade construída pela maneira como a câmera transita pelos

9 Deduz-se que Bachelard está se referindo a capacidade de representação do mundo externo pelo aparelho psíquico. (CF. J. Puget) 
espaços e os mostra sem obstáculos (como portas e objetos). Simbolicamente, o personagem está tão inserido em seu ambiente que nada lhe causa impedimento de locomoção.

O primeiro trecho corresponde à sequência de abertura do filme. Vai de oo:09 até 01:41. Possui vinte planos, sendo dez deles cartões que apresentam a equipe técnica. As imagens são planos-detalhe de objetos cênicos. Eles constroem uma visão bastante próxima, em detalhe, de inúmeros elementos componentes de um espaço descontinuado pelos cartões. Há um efeito de borrão na imagem que ocorre nos planos não cartões de introdução da equipe, conforme pode ser conferido abaixo:

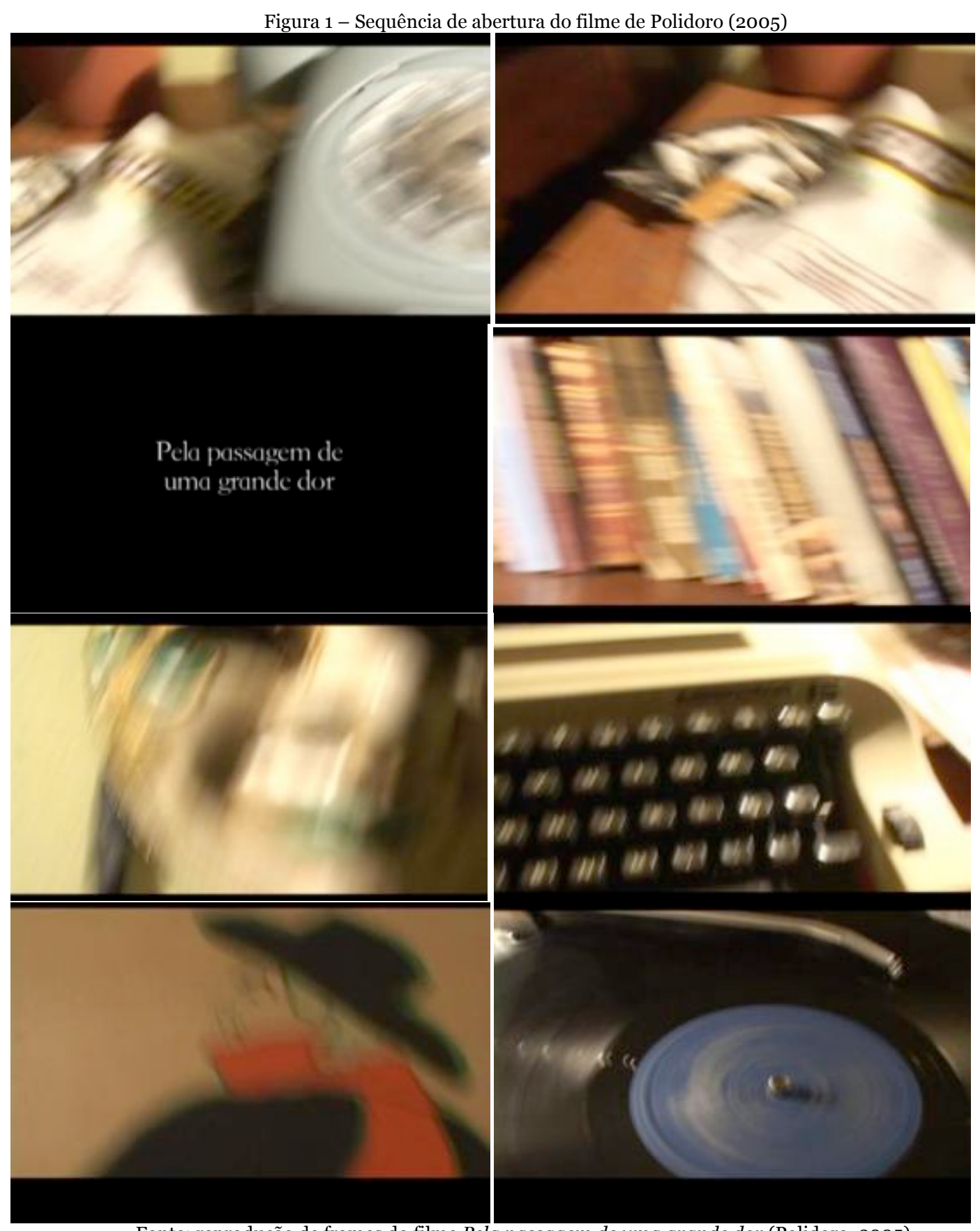

Fonte: reprodução de frames do filme Pela passagem de uma grande dor (Polidoro, 2005). 
A primeira questão para a qual se chama atenção na primeira sequência é a curta duração de primeiros planos intercalados por cartões que apresentam a equipe. Em segundo lugar é notada a intervenção técnica que reorganiza a impressão de fluidez das imagens. Embora seu fluxo permaneça inalterado, sua percepção sofre uma modulação através da proposta aplicada. Este desenrolar lento e borrado configura uma ação técnica de montagem, ou um efeito de câmera. De ambas as maneiras, obtém-se uma interferência na imagem que a diferencia de um registro "natural". Reisz e Millar (1968) comentam que uma sequência é composta de planos que são "heterogêneos em tempo e espaço" (Reisz; Millar, 1968: p.65, tradução do autor). A interferência provocada na imagem se configura como uma intervenção capaz de reorganizar a leitura do tempo e do espaço. Trata-se, simbolicamente, de uma vivência em um espaço tão isolado do resto do mundo que possui sua própria dinâmica de movimento, de espacialidade e de transgressão do tempo contínuo.

Através disso aparecem os primeiros indícios de uma formação simbólica do espaço da casa e uma possível intimidade a ser lida nela: há um ponto de vista que introduz estes pequenos espaços e cuja roupagem estética se assemelha a de uma percepção alterada. Seja por um sonho ou por questões "psico-bioquímicas" que afetam esse olhar. Não se trata de uma visão clara, mas de um convite para que se perceba uma sensibilidade que constrói estes recortes através de um determinado estado e afeto. Como propõe Gastón Bachelard, percebe-se aqui uma ênfase no sentir o espaço e objetos, muito antes e talvez mais do que decifrá-los. Esta questão aparece logo no princípio da Poética de Bachelard quando o autor comenta que: "É necessário estar presente, presente à imagem no minuto da imagem" (Bachelard, 2012:01). A intervenção na mostração do espaço (re)presentifica a imagem. As próprias imagens da sequência dizem: trata-se de uma casa borrada e fragmentada. Uma particularidade estética que nos ensina a perceber e exercitar um habitar que é particular daquilo que está por vir na narrativa.

A composição cenográfica aponta para uma configuração estética expressiva. Há um destaque para cada elemento componente da casa: Telefone, cigarros, livros, objetos decorativos, máquina de escrever, toca-discos. A interpretação que leva a uma conclusão de "destaque" estabelecido por essas imagens se dá pela sua própria predominância em cada plano. Objetos que, fora de um recorte fílmico, figuram como mundanos, ganham uma ocupação quase na totalidade do quadro10. Os espaços mostrados em cada plano são visões íntimas de objetos próprios de alguém, e que traduzem o próprio habitar (Bachelard, 2012).

O segundo trecho que trabalha a noção simbólica do habitar no filme de Polidoro vai de 01:41 até 03:15. Tem aproximadamente três minutos e meio de duração e possui 04 planos. O primeiro plano tem aproximados quarenta segundos de duração. Em plano-médio ele mostra o televisor e faz uma panorâmica da esquerda para a direita até enquadrar o personagem Lui sentado no sofá. O segundo plano tem sete segundos de duração e é um plano aberto em travelling-out. Nele o personagem caminha lentamente pelo corredor do apartamento que liga a sala ao quarto após ouvir o telefone tocar. O terceiro plano tem um telefone em primeiro plano, em destaque, e ao fundo a porta por onde Lui entra, também tem sete segundos de duração. O quarto plano tem 
aproximadamente um minuto e meio de duração e mostra em plano-aberto Lui atendendo o telefonema enquanto se acomoda na cama.
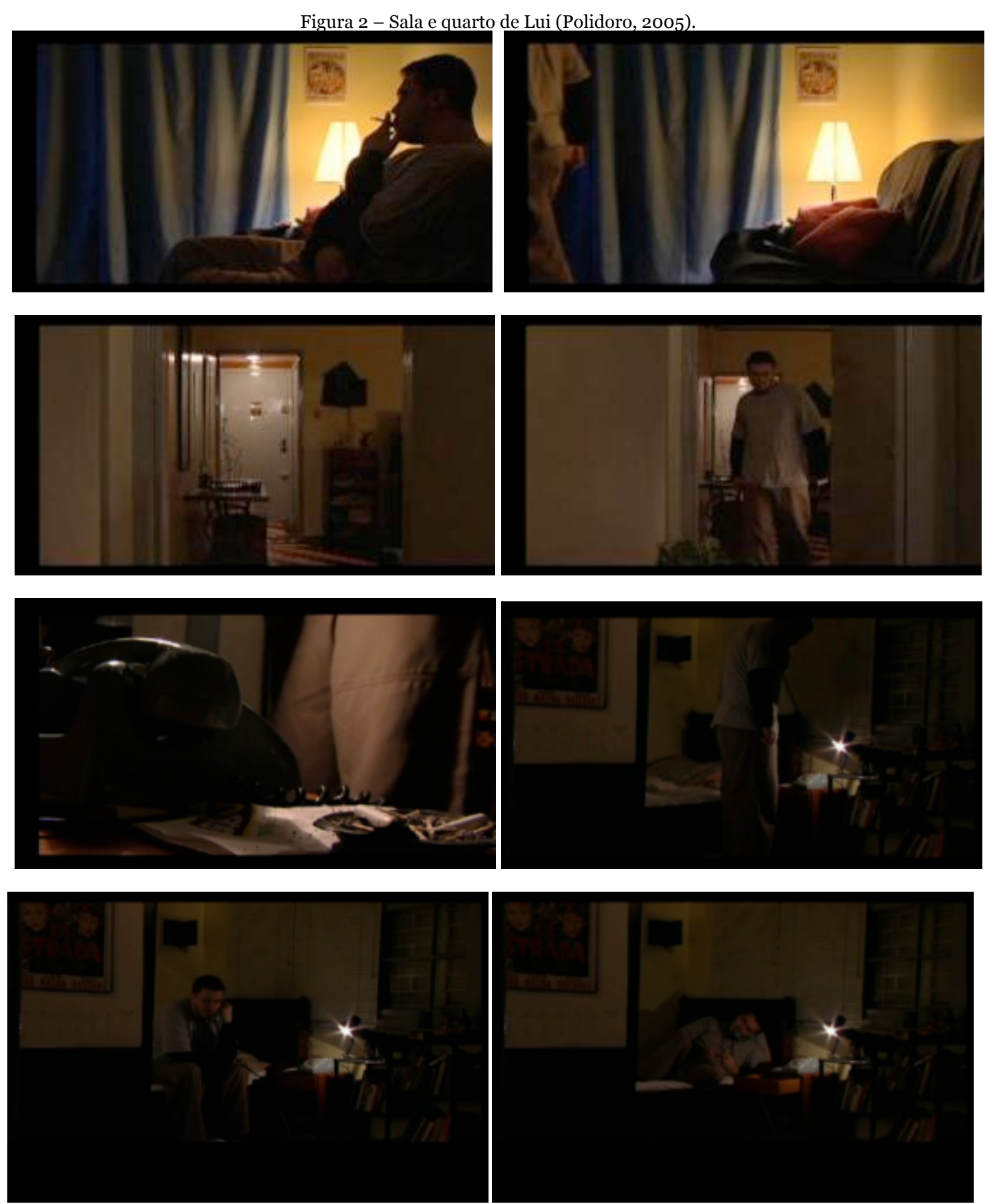

Fonte: reprodução de frames do filme Pela passagem de uma grande dor (Polidoro, 2005).

Junto com a sequência anterior é possível perceber a apresentação da totalidade da casa de Lui. Todos seus espaços habitados ao longo do filme, neste ponto, já são conhecidos e, conforme os planos vão se sucedendo, nos é possível compreender a maneira como o personagem se relaciona com a sua própria forma de habitar seus espaços e como isso é criado visualmente na imagem fílmica. Sua casa possibilita a leitura de uma intimidade habitada de proteção e 
clausura. Sua interação com os ambientes aponta para uma dupla inserção, ele habita a casa tanto como ela o habita, assim como Bachelard propõe (Bachelard, 2012:19). Essa dupla inserção parece ser uma das questões fundamentais na criação desta forma de uma estética visual pautada pelo habitar. Nesta sequência foram percebidas diferentes expressões do vazio, algo figurando em coro com a proposta de reclusão habitada de Bachelard: Vive-se a reclusão pelo vazio. Não se trata de um vazio "triste", mas de um espaço em que a solidão e a intimidade do aconchego são inabaláveis, mesmo pelos poucos objetos que estão lá. Há um "cheiro" de velho nas imagens da casa de Lui que remete a um passado. Nas palavras de Bachelard: "Os verdadeiros bem-estares têm um passado. Todo um passado vem viver, pelo sonho, numa casa nova" (Bachelard, 2012:25).

Nas reproduções dos frames correspondentes à caminhada do personagem pelo corredor pode-se perceber uma troca de perspectiva: $O$ ponto de vista anterior se organizava de maneira contemplativa, quase isento de qualquer possível interferência no que enuncia imageticamente. Já o subsequente se organiza através de uma construção em movimento, que acompanha o personagem quase como se estivesse fugindo dele, em um recuo de câmera. Aliado disso, o espaço amplo, de canto, dá lugar a uma forma claustra. Como num brete, sem outra possibilidade de direção, o personagem é conduzido mais do que se conduz. Há uma impressão labiríntica trazida pelo enquadramento também, proposta através da visualidade das paredes laterais esgueirando-se na imagem.

Embora Bachelard não se preocupe com o cinema, sua proposta de espaço encontra eco em diversas formas de expressão. Encontrar ocorrências de sua proposta no cinema não chega a configurar uma surpresa, mas um atestado de que as expressões culturais de cada época evocam as diferentes simbologias dos espaços. Talvez, enquanto conjunto cultural e social, tenhamos um gosto latente por inscrever-nos em espaços e desfrutar do abrigo para nossas solidões e intimidades uns com os outros. Uma estética visual do habitar pode claramente ser criada a partir das potencialidades fílmicas e leva adiante fomentos trazidos da parte literária dando-lhes uma nova vida e novos significados.

\section{Considerações finais}

O espaço enquanto uma construção técnica explora as potencialidades de cada questão que o abarca no desenvolvimento de um filme. Desde o estabelecimento da narrativa a ser mostrada já se tem pré-espaços; demandas por lugares que abrigam não só a ação, mas a simbologia de afetos envolvidos nas relações dos personagens entre si e com a trama a ser desenvolvida. Foto, arte, montagem, encenação e som emprestam as suas características para romper, modelar e compor um espaço que não necessariamente se dá de maneira análoga ao real. Suas idiossincrasias se inserem na imagem e possibilitam uma leitura por parte do espectador frente o diálogo com os códigos culturais partilhados e envolvidos.

Por sua vez, a construção simbólica do espaço pode lidar com inúmeros sentimentos e leituras. A intimidade, como tratada neste estudo, se comporta como uma das possibilidades inscritas no espaço. Trabalhos futuros podem se pautar por Bachelard, ou algum outro autor, para explorar os outros sentimentos simbolizados na imagem do espaço. Por exemplo, as teorias ligadas 
ao cinema de horror já consideraram o espaço enquanto uma instância macabra; com diversos tipos de protagonismo dentro da narrativa e da imagem.

Retomando a pergunta de pesquisa, "como o processo adaptativo amplia as possibilidades de uma memória cultural de uma narrativa?" pode-se observar que há sim uma possibilidade de ampliação relacionada à hipótese levantada neste estudo. O processo adaptativo, ao lidar com diferentes formas de influência e objetos fonte, reorganiza o objeto original e lhe dá novas interpretações, sendo uma delas a potencialidade visual proporcionada pelo formato fílmico.

Ao ser trazido para a forma fílmica, o objeto literário é colocado em uma outra situação enunciativa capaz de trazer à tona questões latentes não apenas ao formato original, mas ao universo estético de relações com as quais estabelecia algum toque.

O caso de Pela passagem de uma grande dor é notório, pois o conto, majoritariamente um diálogo, traz poucas informações sobre o espaço e a maneira como os personagens se relacionam com este espaço. Ao ser adaptado, a equipe, colaborativamente, opta por uma criação que dá ênfase, ou possibilita a leitura, de uma relação do personagem com seu próprio habitar os lugares que opta. Essa criação amplia a rede de significados possibilitados pelo conto e traz marcas sobre a maneira como criamos imagens dos nossos espaços hoje e como nos remetemos a espaços passados, dialogando com estéticas já estabelecidas anteriormente, neste caso com as questões culturais dos anos 80 .

A ampliação da memória de uma narrativa pelo reelaboração estética de suas potencialidades pode ser observada, no caso de uma estética do habitar, a partir das simbologias propostas por Bachelard. À luz da Poética do espaço (2012), pode-se perceber as marcas humanas que compõe nossa relação com os espaço e como se dá a intimidade de habitar os lugares que habitamos, muitas vezes convertendo espaços não casa em casas aconchegantes e aninhadoras de nossas questões mais íntimas.

\section{Referências}

ABREU, Caio F. Morangos Mofados. Rio de Janeiro, RJ: Nova Fronteira, 2005.

AUMONT, Jacques (orgs). A estética do filme. $3^{\text {a }}$. ed. Campinas, SP: Papirus, 2005 .

BACHELARD, Gaston. A poética do espaço. São Paulo, SP: Martins Fontes, 2012.

BÂ, Saër Maty. Problematizing (black) documentary aesthetics: John Akomfrah's use of intertextuality in Seven Songs for Malcolm X. Studies in documentary film, v. 1, n. 3, p. 221-244, 2007.

BAZIN, Andre. O cinema: ensaios. São Paulo: Editora Brasiliense, 1991.

BORDWELL, David. Narration in the fiction film. Madison, Winsconsin, EUA: University of Winsconsin Press, 1991.

CATTRYSSE, Patrick. Film (Adaptation) as Translation: Some methodological Proposals. Target: International Journal of Translation Studies, v. 4, n. 1, p. 53-70, 1992. 
ELLIS, John. The literary adaptation. Screen, v. 23, n. 1, p. 3-5, 1982.

HUTCHEON, Linda. A theory of adaptation. New York, NY, EUA: Routledge Publishing, 2006.

JULLIER, Lauret; MARIE, Michel. Lendo as imagens do cinema. São Paulo, SP: Editora Senac São Paulo, 2009.

MILLAR, Gavin; REISZ, Karel. The technique of film editing. Burlington, MA, EUA: Focal Press, 1968.

OLIVEIRA SILVA, Luiza Batista de. A fenomenologia da imaginação na "Poética do espaço" de Gastón Bachelard. Educare et Educare: Revista de educação, v. 8, n. 16, p. 329-341, 2013.

PIMENTEL, Juliano Rodrigues. Aspectos técnicos e simbólicos do espaço fílmico nas adaptações do conto pela passagem de uma grande dor de Caio Fernando Abreu. Dissertação, Programa de Pós-Graduação em Comunicação e Informação da Universidade Federal do Rio Grande do Sul, Porto Alegre, RS, 2015 .

PORTO, Luana Teixeira. Morangos Mofados, De Caio Fernando Abreu: Fragmentação Melancolia e Crítica Social. Dissertação, Programa de Pós Graduação em Letras: Departamento de Literatura Brasileira da Universidade Federal do Rio Grande do Sul, Porto Alegre, RS, 2005.

SANDERS, Julie. Adaptation and Appropriation. Londres, RU: Routledge Publishing, 2005.

SOUZA, Fabiano de. Caio Fernando Abreu e o Cinema: O eterno inquilino da sala escura. Porto Alegre: Editora Sulina, 2011. 